\title{
Experiências com a escrita na pós-graduação brasileira: uma proposta de diálogo com os letramentos acadêmicos
}

\author{
Guilherme Brambila ${ }^{1}$ \\ Programa de Pós-graduação em Estudos Linguísticos, Universidade Federal do Espírito Santo, Vitória, ES, Brasil
}

Resumo: Este trabalho tem como objetivo principal discutir os lugares da escrita na pós-graduação brasileira. Para isso, realiza uma análise de postagens de pós-graduandos que relatam experiências com esse processo na rede social Facebook. O estudo guia-se pelos pressupostos dos letramentos (STREET, 1995; GEE, 2001), com foco na proposta de estudo dos letramentos acadêmicos no contexto brasileiro (FISCHER, 2010; FIAD, 2011). Metodologicamente, a análise guia-se pelo paradigma indiciário (GINZBURG, 1986), reconhecendo os dados de pesquisa como autenticamente dialógicos (BAKHTIN, 2011). Como resultado, o trabalho indica que há uma percepção complexa acerca da escrita na pós-graduação brasileira, associando-a como prática que transforma as formas com as quais o pós-graduando enxerga a si e suas relações de trabalho nesta esfera.

Palavras-chave: Escrita; Pós-graduação; Letramentos acadêmicos.

Title: Writing experiences in Brazilian graduate courses: proposing a dialogue with academic literacies Abstract: This paper aims at discussing the places of writing in the Brazilian graduate courses. To do so, it develops an analysis of graduate students' posts about their experiences with this process in the Facebook social network. The study is guided by literacy studies (STREET, 1995; GEE, 2001), focusing on the academic literacy investigation proposals in the Brazilian context (FISCHER, 2010; FIAD, 2011). Methodologically, the analysis is guided by the indiciary paradigm (GINZBURG, 1986), recognizing the research data as authentically dialogical (BAKHTIN, 2011). As a result, the study indicates that there is a complex perception about writing in the Brazilian graduate courses, relating it as a practice that transforms the ways the graduate sees him/herself and his/her working relationships in this place.

Keywords: Writing; Graduate course; Academic literacies.

\footnotetext{
${ }^{1}$ Mestre em Estudos Linguísticos pela Universidade Federal do Espírito Santo. Doutorando em Estudos Linguísticos pela mesma instituição. Professor de Língua Portuguesa da Rede Estadual de Educação Básica do Espírito Santo (SEDU-ES). Orcid: http://orcid.org0000-0001-7978-5020.

E-mail: guilhermebrambilamanso@hotmail.com.
} 


\section{Apresentação}

A experimentação da escrita, desde a mais tenra idade, é um processo no qual os sujeitos colocam em movimento ações que ultrapassam a mecânica do desenho de palavras. Ao observarmos, por exemplo, crianças na fase da alfabetização (o que na escola formal acontece do 10 ao 20 ano do Ensino Fundamental), temos a clareza de que o desenvolvimento da escrita torna-se cada vez mais complexo à medida que o sujeito vai tomando consciência das redes de interação humana possíveis de serem estabelecidas a partir da concretização dos enunciados no plano verbal.

Por consequência, os mesmos sujeitos que outrora deram início à prática do escrever são confrontados com um processo de normatização da vida humana na e pela linguagem escrita, que representa em nossa sociedade ocidental a culminância formal de tratados, rituais jurídicos, acadêmicos etc.

Dentre os incontáveis lugares em que a vida dos sujeitos é atravessada pela escrita é possível mencionar a esfera acadêmica, que se estabelece a partir de uma variedade de produções escritas consolidadas como elementos constitutivos desse lugar. Pela escrita, o sujeito adentra o meio acadêmico - visto o peso que a nota de redação do Enem (Exame Nacional do Ensino Médio) tem no ranqueamento de candidatos a vagas em universidades públicas e ao pleito de bolsas em instituições privadas - e só por meio da mesma que, muitas vezes, ele sairá - o grande exemplo, para muitos cursos de graduação no Brasil, é a escrita do Trabalho de Conclusão de Curso (TCC).

Contudo, há ainda uma parcela da comunidade acadêmica que opta por permanecer mais um tempo dentro deste lugar, ao entrar nos cursos de pós-graduação. Em especial, as modalidades de curso stricto sensu, correspondente aos mestrados e doutorados, são etapas nas quais haverá não só uma intensificação de expectativas intelectuais, mas também de supostas novas habilidades com escrita que o sujeito pós-graduando precisará demonstrar até o fim deste percurso.

A escrita na pós-graduação é uma realidade que, pelas próprias normativas que regem os programas brasileiros, não pode ser ignorada. Desde os pós-graduandos aos seus professores/orientadores, a escrita na pós-graduação atravessa as relações intersubjetivas, sendo com frequência uma representação da intelectualidade humana.

Apesar de não ser o único, um grande exemplo de prática com a escrita na pósgraduação stricto sensu brasileira encontra-se no processo de produção da dissertação, para os mestrandos, e da tese, para os doutorandos. Tal tarefa, que é tomada como responsabilidade do início ao fim da pós-graduação, compõe uma prática que constitui um dos grandes ritos de passagem do graduado para o alcance do título de mestre ou de doutor. 
Diante de um espaço tão relevante na vida do pós-graduando, a escrita da dissertação/tese configura-se como uma atividade não somente técnica de transposição dos dados científicos aos moldes do gênero acadêmico, mas também de natureza discursiva e ideológica, movimentando a subjetividade do autor, que, pela via da linguagem, precisará lidar com todas as possíveis tensões que compõem a construção do texto, além dos entornos sociais no meio acadêmico.

Outro ponto que justifica tamanha relevância está no próprio status da dissertação e da tese à sociedade acadêmica. Se para a comunidade acadêmica a dissertação/tese representa a concretude de um percurso de trabalho que se tornará referência e suporte para a continuação do fazer científico, para o pós-graduando essa escrita simboliza o ganho de identidade e pertencimento ao posto de pesquisador, como culminância de um processo percorrido durante os anos de dedicação na pós-graduação.

Também refletem sobre a noção de pertencimento na comunidade acadêmica pela via da escrita Fischer e Hochsprung (2017, p. 48), ao afirmarem que

\begin{abstract}
Entende-se, dessa forma, que se iniciam manifestações autorais durante as primeiras experiências com práticas de escrita de um primeiro ano de curso, mas que continuam em processo durante toda a vida acadêmica. Gee (2001), ao abordar o conceito de insider - membro efetivo em práticas de letramentos - contribui para esta discussão. Para este autor, as identidades se constroem a partir de quando e de como os sujeitos são inseridos em práticas do contexto acadêmico, o que remete aos modos como esses sujeitos interagem com e nessas práticas que incluem a escrita acadêmica.
\end{abstract}

Apesar de o estudo dos autores ter seu foco no processo de escrita acadêmica dentro da graduação, pensar esse mesmo processo na pós mostra-se como uma discussão que deve ser encarada como complexa, exigindo dos estudos da linguagem o acionamento de debates que alcancem a vida dos sujeitos que vivenciam esta etapa de trabalho e aprendizagem.

Desta forma, este artigo apresenta-se como uma contribuição aos estudos da linguagem, com identificação específica em Linguística Aplicada, por analisar enunciados de pós-graduandos a respeito do processo de escrita de suas dissertações/teses em um grupo da rede social Facebook, na perspectiva de construir considerações a respeito das relações estabelecidas com a linguagem pelo sujeito pós-graduando no contexto de escrita da pósgraduação brasileira.

Este tipo de discussão se justifica pela necessidade de trazer à tona as vozes dos pósgraduandos, suas percepções, imaginários e expectativas a respeito dos novos entornos que sua relação com a linguagem precisa alcançar no âmbito da pós-graduação. Ainda, ressaltamos a necessidade de abrir diálogos cada vez mais frequentes sobre o contexto da pós-graduação, a fim de trazer melhorias e suporte para os sujeitos que lá interagem. 
Para alcançar a proposta, o estudo pretende percorrer os pressupostos dos letramentos acadêmicos, dedicando maior atenção à interface contributiva desses postulados ao contexto da pós-graduação. É também pretendido discorrer a respeito da pós-graduação brasileira, focalizando o diálogo no processo de escrita dentro desse meio. Por fim, serão analisadas algumas postagens feitas por pós-graduandos no grupo da rede social Facebook chamado "Bolsistas Capes" a respeito da escrita da dissertação/tese. Os dados são observados dialogicamente (BAKHTIN, 2011), além de serem reconhecidos como indícios (GINZBURG, 1986) nunca fechados da realidade, mas que refletem e refratam a vida dos sujeitos no contexto da pós-graduação brasileira.

\section{Letramentos acadêmicos na pós-graduação: de que estamos falando?}

A partir do que foi discutido na seção introdutória, temos em vista um tema que precisa ser pauta dos estudos linguísticos que se endereçam à vida acadêmica: a escrita na pós-graduação. A partir desta prática com a linguagem em um meio que se caracteriza pela interação de sujeitos atravessada pelo discurso acadêmico, emerge a possibilidade de trabalhar tal assunto sob a ótica dos letramentos acadêmicos.

Todavia, caberia a nós o questionamento: de que maneiras os postulados dos letramentos acadêmicos dão suporte a uma problemática tão específica quanto as relações com a escrita tidas pelos sujeitos da pós-graduação? Na perspectiva de traçar, ao menos, um possível plano de trabalho, esta seção visa a estabelecer pontos de interseção entre as preocupações dos letramentos acadêmicos com o contexto linguístico-discursivo da pósgraduação.

Ao mencionarmos o termo "letramentos", evocamos por consequência as vozes de Gee (1999), Street (1995), Barton e Hamilton (2000), que contribuíram e contribuem ao entendimento das práticas de leitura, escrita e produção de sentidos como movimentos que estão constantemente atrelados à vida social (cf. GEE, 2001). Dentre as contribuições na seara dos letramentos encontramos os letramentos acadêmicos, que se diferenciam por focalizar suas discussões e trabalho às práticas diversas com a linguagem, considerando as circunstâncias e discursos que atravessam o meio acadêmico especificamente. Tal cenário nos provoca a pensar que lidamos com uma proposta de letramentos diferente, mesmo que parta de uma mesma matriz e propósito.

Street (2007) traz um esclarecimento pertinente a respeito da existência de letramentos diferentes, ao afirmar que

Diferentes letramentos, portanto, são associados a diferentes pessoalidades e identidades. Conjuntos semelhantes de associações podem ser vistos nesta cultura, uma vez reconhecida a importância do letramento para tais processos. Quando freqüentamos um curso ou uma escola, ou nos 
envolvemos num novo quadro institucional de práticas de letramento, por meio do trabalho, do ativismo político, dos relacionamentos pessoais, etc., estamos fazendo mais do que simplesmente decodificar um manuscrito, produzir ensaios ou escrever com boa letra: estamos assumindo - ou recusando - as identidades associadas a essas práticas. A idéia de que as práticas de letramento são constitutivas de identidades fornece-nos uma base diferente - e eu argumentaria: mais construtiva - para compreender e comparar as práticas de letramento em diferentes culturas, alternativa à ênfase corrente numa simples dicotomia letramento/iletramento, em necessidades educacionais como inevitavelmente endêmicas ao letramento e no tipo de letramento associado com uma pequena subcultura acadêmica, com sua ênfase no texto ensaístico e na identidade típica a ele associada. (STREET, 2007, p. 470).

Interessa a partir do que assevera Street compreender que os letramentos precisam ser enxergados como práticas com a leitura e escrita não estanques, isto é, que se estabelecem, metamorfoseiam-se e são agregadas de novas identidades de maneira conjunta ao tempo-espaço em que são colocadas em ação. Assim, pensar em práticas de letramento acadêmico requer um olhar que dialogue com as circunstâncias de estabelecimento da interação humana via linguagem, alcançando as demandas da formação superior, que se distinguem de outras esferas.

A respeito do letramento acadêmico, também concordamos com a definição dada por Fiad (2011, p. 362), quando afirma que:

É possível falar em letramento acadêmico: assume-se que há usos específicos da escrita no contexto acadêmico, usos que diferem de outros contextos, inclusive de outros contextos de ensino. Embora alguns estudiosos entendam o conceito de letramento acadêmico compreendendo todo contexto onde há práticas formais de escolarização (por exemplo, FISCHER, 2008), prefiro considerar letramento acadêmico como restrito ao contexto universitário, embora saiba que há práticas de letramento comuns a todos os contextos escolares, sejam da educação básica até a universidade.

Assim como Fiad, este trabalho segue a perspectiva que defende a tomada de consciência das especificidades das esferas de interação humana. Todavia, assim como a autora desenvolve, esta tomada não pode acontecer de maneira unicamente rotular, isto é, que agregue aos letramentos um adjetivo que seja meramente acessório. Por outro lado, é necessário tomar as especificidades de cada proposição de letramento como um plano de trabalho distinto, no qual sujeitos com noções ou vontades de pertencimento a este plano circulam e que, por consequência, provocam interações sociais a serem culminadas em produções linguístico-discursivas, sempre dentro de uma coerência dialógica.

Diante de tal demanda e responsabilidade, o trabalho dos letramentos acadêmicos se faz necessário, pois se constitui de um campo dentro dos estudos linguísticos que abre espaço 
ao debate e entendimento das relações socioculturais que se estabelecem discursivamente na esfera acadêmica. Ainda, é através de uma prática comprometida com os letramentos acadêmicos que são extraídos suportes de análise a partir da linguagem para uma melhor compreensão acerca dos sujeitos, suas identidades e locais de fala.

Nos letramentos acadêmicos é possível encontrar um recorrente interesse pela vida do sujeito estudante de graduação. Trabalhos como os de Fischer (2010), Fiad (2011), Alves e Moura (2016), Cerutti-rizzatti e Dellagnelo (2016) e Bessa (2016) são alguns exemplos de ricas contribuições às discussões dos letramentos acadêmicos, especialmente quando o interesse for o contexto brasileiro. Todavia, notamos que há uma demanda pouco preenchida pelos estudos linguísticos por discussões com enfoque na pós-graduação. Por quê?

É possível especular sobre uma aparente baixa de discussões e planos de ação dos estudos linguísticos no contexto da pós-graduação. Lançamos, portanto duas principais hipóteses: a primeira refere-se a um possível imaginário de sapiência plena nos entornos da pós-graduação, o que provocaria a impressão de desnecessidade da promoção de suportes que auxiliem linguisticamente esses sujeitos; a segunda refere-se ao fato de que investigar e problematizar as práticas de linguagem na pós-graduação demandaria ao linguista um processo de análise tanto pessoal quanto de seu próprio espaço de fala, tarefa que pode se configurar como demasiadamente complexa.

A respeito da primeira hipótese, arguimos que a baixa de debates sobre as práticas com a linguagem na pós-graduação, especialmente as que dizem respeito ao processo de escrita da dissertação/tese, se daria pelo imaginário de que o pós-graduando não encararia o meio acadêmico como um lugar novo, mas sim como uma esfera, em algum aspecto, já reconhecida. Tal percepção, apesar de plausível, tende a ignorar certas relações de trabalho, discursivas e linguísticas que são próprias única e exclusivamente da pós-graduação. Como exemplo, podemos citar a nova relação com o produto da escrita durante a orientação de mestrado, quando comparada à orientação de um Trabalho de Conclusão de Curso, na graduação. Apesar de um claro reconhecimento de que há um pressuposto de escrita diferenciado na pós-graduação, em (quase) nada essa ideia auxilia de maneira prática à vida do pós-graduando a vivenciar uma experiência de escrita menos desgastante.

Sobre a segunda hipótese, indagamos que há, dentro da própria concepção identitária do pesquisador, a crença do serviço ao outro (entendido aqui em seu sentido lato) em detrimento de um autocuidado. Independente da área de atuação, o sujeito pesquisador desenvolve, cria e debate a ciência com um olhar constante a uma causa que o incomode ou que se interesse em contribuir intelectualmente em sociedade, com vistas a fomentar caminhos de melhoria social. Todavia, e com base em dados obtidos por pesquisa desenvolvida pela Associação de Pós-graduação da Universidade de Brasília (APG-UNB, 2018), a pós-graduação tem adoecido cada vez mais, contabilizando taxas preocupantes de suicídio relacionadas ao ritmo de trabalho desenvolvido na esfera acadêmica brasileira. 
A partir dos dados da pesquisa da UNB, são detectados altos índices de ansiedade, depressão e seus desdobramentos na comunidade acadêmica. Tal cenário, segundo a investigação, é gerado por vários motivos, como as interações com professores, colegas e com a própria instituição acadêmica, o desmonte financeiro da pós-graduação, a cobrança pelo rendimento e produtividade em disciplinas e na produção da dissertação/tese, entre outros.

Tendo como ponto de partida a problemática relatada pela investigação da UNB, adicionada à observação do dia a dia do pós-graduando brasileiro, que os estudos em letramentos acadêmicos se fazem ainda mais necessários. Isso se justifica por compreendermos que todas as relações e práticas relatadas no parágrafo anterior, causadoras de sofrimento pela pós-graduação brasileira, são atravessadas pela linguagem. Até mesmo na compreensão de que o problema enfrentado pela pós-graduação tenha uma base sociológica é na e pela linguagem que se estabelecem os tratados hierárquicos, demarcações de poder e violência simbólica.

Os letramentos acadêmicos, então, mostram-se como um movimento linguístico e pedagógico necessário ao contexto da pós-graduação. Por meio do desenvolvimento de pesquisa e da discussão dos lugares da escrita na vida dos pós-graduandos que conseguimos construir caminhos de investigação que proporcionem uma experiência dialógica com a linguagem a esta esfera como um todo. Consideramos tal potencialidade a partir de Fiad (2015, p. 30), quando afirma que "uma das contribuições vindas dos estudos do letramento à nossa tradição de pesquisas sobre a escrita é trazer a perspectiva etnográfica como uma possibilidade de construir uma articulação entre o texto e o contexto na abordagem da escrita".

Outro fator que justifica o lugar dos letramentos acadêmicos nos estudos da vida do pós-graduando e de seu relacionamento com as produções escritas do meio acadêmico é seu olhar especializado às demandas da pós-graduação no tocante da identidade linguísticodiscursiva. Importa mencionar que preocupação com a (não) qualidade de vida na pósgraduação já é alvo de investigação de pesquisadores concentrados nas áreas de Psicologia, Ciências Sociais e Educação (CRUZ, 2018; SANTOS, GARCIA, AQUINO, 2017, para citar alguns exemplos), porém notamos que há a necessidade de a Linguística Aplicada tomar para si também essa responsabilidade, já que se estabelece contemporaneamente com o objetivo de "falar ao mundo em que vivemos, no qual muitas das questões que nos interessavam mudaram de natureza ou se complexificaram ou deixaram de existir" (MOITA LOPES, 2009, p. 19).

Em suma, as considerações norteadoras desta seção concentram-se em conceber os letramentos acadêmicos como um campo profícuo de discussões relacionadas à escrita e a demais práticas com a linguagem na pós-graduação. Compete, portanto, ao linguista a responsabilidade de redirecionar de maneira crítica os pressupostos básicos dos letramentos acadêmicos à esfera da pós-graduação, considerando principalmente as identidades e relações de poder que são particulares desse meio, diferentemente do ocorrido na graduação. A fim de dar continuidade ao que foi desenvolvido até aqui, a próxima seção concentrará sua 
discussão no debate da escrita na pós-graduação e seus desdobramentos às concepções de linguagem e de gênero do discurso.

\title{
Escrever na pós-graduação: compreendendo dimensões
}

Nesta seção, especificamente, temos como principal objetivo o debate de duas interfaces complexas e que ganham desdobramentos particulares na pós-graduação: a compreensão de linguagem e de gênero do discurso. Para fomentar essa discussão, tomamos como referência os pressupostos do Círculo de Bakhtin, que postulam noções pertinentes para a compreensão não só da interface linguístico-discursiva, mas também histórico-social, ideológica e dialógica que compõe esses campos.

Justificamos também a proposta de trazer as considerações do Círculo para a discussão da escrita no contexto acadêmico com base em Marinho (2010, p. 367), que afirma que

\begin{abstract}
Bakhtin, um nome de referência nos estudos contemporâneos sobre a linguagem, numa perspectiva sócio-cultural enunciativa, nos dá um forte e conhecido argumento para se repensar uma certa maneira com que se lida com as dificuldades de leitura e de escrita dos alunos na universidade: o domínio de um gênero é um comportamento social. Isso significa que é possível ter um bom domínio da língua, mas ser inexperiente na atividade de moldar os gêneros, de administrar a interação, a tomada de turnos, etc. A experiência é algo constitutivo da prática nas comunidades que fazem uso de determinados gêneros, tornando-se, assim, condição indispensável para uma interação verbal bem-sucedida.
\end{abstract}

Assim, esta seção está organizada na compreensão das concepções de linguagem e de gênero discursivo a partir do Círculo de Bakhtin, com vistas a estabelecer contraponto com o contexto da pós-graduação e suas particularidades.

Importa destacar que o pensamento do Círculo repele a ideia do objetivismo abstrato diante da língua e linguagem. Veremos que no pensamento do Círculo acerca da língua, enquanto norma e enquanto parte da vida dos sujeitos, há uma distinção clara que nos afasta do erro de se pensar a normatização linguística como algo implacável, cristalizando a língua em um modus sincrônico de existência.

Se dissermos que a língua como sistema de normas indiscutíveis e imutáveis existe de modo objetivo, cometeremos um erro grave. No entanto, se dissermos que a língua na concepção da consciência individual é um sistema de normas indiscutíveis e imutáveis, que esse é o modus de existência da língua para cada um dos membros dessa coletividade linguística, expressaremos uma concepção totalmente objetiva. Mas será que o próprio fato foi estabelecido corretamente, será que a língua na consciência do 
falante seria apenas um sistema de normas imutável e imóvel? (VOLÓCHINOV, 2017, p. 175).

Com base nesta noção notamos a identidade, nunca enclausurada, da concepção de língua e linguagem para o Círculo. Compreendemos assim que a concepção de língua e linguagem se estabelece em duas frentes: dentro de um sistema, como um produto de reflexão que não se dá na consciência do falante, mas que se elabora como objeto não relacionado às mudanças demandadas pela interação social; e na vida do falante, como constituinte de enunciados concretos que são atravessados ideologicamente pelos sujeitos, contextualizada e participante de processos de emissão e recepção. De acordo com Volóchinov (2017, p. 177), "para um falante a forma linguística é importante não como um sinal constante e invariável, mas como um signo sempre mutável e flexível".

Façamos, a partir desses pressupostos, um paralelo com o contexto da pós-graduação. Compreendemos que, ao ingressar no contexto da pós, o sujeito acopla a sua vida responsabilidades com a produção escrita acadêmica, o que requisitará uma tomada de atitudes em relação à linguagem que buscarão aplicação em uma esfera com a qual ele nem sempre terá um lugar dialógico de fala.

Ainda tomando como exemplo os dados da pesquisa que revelam os índices de desmotivação na pós-graduação, é possível interpretar que o ambiente no qual o pósgraduando precisará compor a escrita de sua dissertação/tese oferece inúmeros fatores que vão contra essa tarefa. Características da pós-graduação relatadas na pesquisa, como o isolamento social, apatia e o próprio bloqueio de escrita, são indícios de que para o estudante há uma pressuposição de silenciamento frente a um discurso monológico que rege o sistema da pós-graduação brasileira. Diante de tal condição, as possibilidades de uma construção enunciativa pela via da linguagem e que se refletem na escrita da dissertação/tese são drasticamente comprometidas.

Uma consequência do cenário relatado no parágrafo anterior é um relacionamento não dialógico com a escrita na pós-graduação. Em outras palavras, os fatores listados podem facilmente levar o sujeito pós-graduando a uma prática com a escrita desconectada da interface subjetiva e autoral que também é necessária neste meio. Contrariamente, é possível inferir que o pós-graduando passará a reconhecer a composição escrita de sua dissertação/tese como algo próximo de uma composição textual monológica, afastando-se de sua autoconstrução de sujeito pesquisador na e pela linguagem.

Para melhor debatermos as interações do sujeito com o entorno discursivo e textual da dissertação/tese em seu processo de escrita, precisamos considerar também os postulados do Círculo sobre os gêneros do discurso, compreendendo a dissertação ou a tese como um deles.

Os gêneros do discurso, a partir do pensamento bakhtiniano, constituem-se de bases social, histórica e dialógica com a linguagem. "O emprego da língua efetua-se em forma de 
enunciados (orais e escritos) concretos e únicos, proferidos pelos integrantes desse ou daquele campo da atividade humana" (BAKHTIN, 2011, p. 261). Ao propor a constituição social e histórica do enunciado, Bakhtin nos instiga à percepção de que os gêneros do discurso, sendo "tipos relativamente estáveis de enunciados" (Ibid., p. 262), seguirão a mesma natureza, tendo sua constituição na e pela interação social. Filho e Torga (2011, p. 4), ao também refletirem sobre a noção de gênero discursivo, declaram que "o que constitui um gênero é a sua ligação com uma situação social de interação, e não as suas propriedades formais". Tomamos, portanto, a compreensão de que refletir sobre o gênero discursivo nos leva à enunciação conjunta de aspectos sociais, políticos e ideológicos imersos na linguagem.

A partir dos postulados bakhtinianos podemos incluir a dissertação ou tese acadêmica como gêneros do discurso, igualmente atravessados por aspectos sociais, políticos e ideológicos, com a distinção de que são concebidos e majoritariamente compartilhados na esfera científica.

França (2018, p. 59) traz uma discussão pertinente sobre a concepção de tese de doutorado como gênero do discurso. Destacamos a defesa da autora para tal identificação:

Pensar na tese de doutorado a partir dessa perspectiva significa não reduzila a uma escrita elaborada como pré-requisito para conclusão de uma etapa de formação institucional do pesquisador, ou uma unidade convencional formada de sequências frasais, que se encaixam em um sistema normativo. É preciso considerar as regularidades e a criatividade que a constitui. Um enunciado, como aponta Voloshinov (s. d.), implica muito mais que fatores linguísticos, pois nele se configuram o verbal e a situação extraverbal, a qual se constitui por três elementos indissociáveis entre os envolvidos na comunicação: o horizonte espacial comum aos interlocutores, o conhecimento e a compreensão comum do contexto pelos interlocutores e a avaliação comum da situação. Esses elementos, rapidamente verificáveis em enunciados orais como em conversa, se estendem à escrita acadêmica.

A partir dos apontamentos de França, é possível conceber os trabalhos finais de mestrado e de doutorado como gêneros discursivos por conta de sua base estrutural e devido aos processos dialógicos de intercruzamento de vozes referenciais que compõem seus conteúdos. Contudo, e mais uma vez levando em consideração os cenários contemporâneos da pós-graduação brasileira, a produção escrita desses gêneros é constantemente acometida de complicadores que podem conduzir o pós-graduando a uma prática extraída de suas redes de significação.

Diante de tais problemáticas envolvendo a linguagem e o gênero discursivo no plano de trabalho da pós-graduação, que caminhos os estudos linguísticos, seguindo os pressupostos dos letramentos acadêmicos, podem tomar para que práticas não dialógicas sejam devidamente problematizadas e superadas?

Uma das respostas possíveis, a partir da discussão desenvolvida até aqui, é a atenção aos sujeitos que são mais silenciados por esse processo: os estudantes de pós-graduação. 
Como um pressuposto próprio dos estudos de letramento e das bases epistemológicas da Linguística Aplicada contemporânea, os sujeitos atingidos de diversas formas pela violência simbólica e marginalização social na e pela linguagem precisam ser o centro da preocupação do linguista envolvido com uma postura dialógica de observação. É a partir da escuta, diálogo e interesse pelas concepções acerca da escrita na pós-graduação desenvolvidas pelos estudantes que se é possível desenvolver medidas e estratégias que desconstruam uma relação subserviente com a linguagem.

Com vistas a construir uma prática de estudo direcionada a esses sujeitos, movimentamo-nos para a próxima seção do texto, na qual algumas postagens compartilhadas por pós-graduandos em um grupo da rede social Facebook serão analisadas com o objetivo de compreender, mesmo que preliminarmente, que concepções de escrita circulam no discurso da pós-graduação, além da tentativa constante de se entender tal cenário por uma perspectiva dialógica e pautada nos pressupostos dos letramentos acadêmicos.

\section{A escrita e a identidade de pesquisador: um diálogo com as experiências discentes}

O objetivo principal desta seção é realizar um levantamento acerca de algumas formas com as quais os sujeitos da pós-graduação interagem com a escrita no contexto acadêmico. De maneira mais específica, pretende-se, a partir da análise de postagens em uma rede social, compreender de que maneiras a dinâmica com a escrita na pós-graduação produz expectativas e imaginários acerca desta esfera social como um todo.

O norteamento teórico-filosófico deste estudo é de base dialógica (BAKHTIN, 2011), sendo as postagens sobre a escrita na pós-graduação (o corpus) reconhecidas como reflexos e refrações autênticos da enunciação humana realizada na concretude histórica e social da vida. Ainda, os dados são trabalhados como indícios (GINZBURG, 1986) de processos que, por sua vez, são tomados como dialógicos (cf. VIDON, 2003).

Sobre o paradigma indiciário, tomamos a proposição de Ginzburg (1986, p. 151), que apresenta este caminho metodológico pela via da metáfora, relacionando-a à caça e à reconstrução de pegadas:

Por milênios o homem foi caçador. Durante inúmeras perseguições, ele aprendeu a reconstruir as formas e movimentos das presas invisíveis pelas pegadas na lama, ramos quebrados, bolotas de esterco, tufos de pêlos, plumas emaranhadas odores estagnados. Aprendeu a farejar, registrar, interpretar e classificar pistas infinitesimais como fios de barba. Aprendeu a fazer operações mentais complexas com rapidez fulminante, no interior de um denso bosque ou numa clareira cheia de ciladas. 
Ginzburg elucida que a via indiciária de percepção e análise movimenta um olhar de aprendiz sobre o corpus, visto que as investigações baseadas nesse método recorrem sempre a aprendizados e vivências anteriores, o que permite que a identificação de resquícios e brechas identificados no objeto de estudo seja observada sob um prisma mais vívido e dialógico, trazendo as próprias experiências do pesquisador à reflexão, repelindo possíveis abstrações (BRAMBILA, 2017).

Como já mencionado anteriormente, o corpus é constituído de postagens feitas em um grupo da rede social Facebook chamado "Bolsistas Capes". O grupo reúne estudantes e demais usuários interessados em trocas de informação a respeito da vida acadêmica, pós-graduação e oportunidades envolvendo bolsas de fomento, como as da Capes (Coordenação de Aperfeiçoamento de Pessoal de Nível Superior). O grupo possui cerca de sessenta mil membros, de faixas etárias e graus de escolaridade e especializações distintas. Circulam pelo grupo, além de assuntos relacionados à temática da (pós-)graduação, relatos de pesquisa, desabafos sobre a vida pessoal, debates envolvendo o cenário político atual e humor.

Com vistas a realizar um trabalho focado em aspectos que vêm sendo debatidos ao longo deste texto, a análise das postagens terá três perguntas norteadoras: i) que lugar(es) simbólicos a escrita ocupa no enunciado do sujeito?; (ii) de que maneira (s) a escrita transforma a percepção do pós-graduando de si mesmo?; e (iii) como que, pelas experiências de escrita, o pós-graduando percebe sua interação com outros sujeitos e elementos da esfera acadêmica (orientadores, o programa de pós-graduação, a instituição, o sistema de ensino e pesquisa brasileiro etc.). Tratando-se de uma investigação indiciária e dialógica, essas perguntas são tidas como norteadores, sem enclausurar a análise em si mesma.

Tratando-se de um corpus que descreve interações reais na e pela linguagem, envolvendo, assim, relações de trabalho, hierarquias e experiências com a pós-graduação brasileira, quaisquer identificações foram removidas e os enunciados serão transcritos, a fim de se evitar correlações aos seus autores e consequentes exposições. Realizados os devidos esclarecimentos, analisemos o primeiro exemplo:

Quadro 1: Postagem e comentário sobre escrever

Postagem: "Escrever é a pior parte para mim. Produzir um texto elegante dá muito trabalho!"

Comentário sobre a postagem: "Pesquisa sem escrita são somente dados".

Fonte: Comentaristas anônimos A e B (2018).

Partiremos do enunciado que compõe a postagem, no qual o sujeito assevera que a escrita é a pior parte (Comentarista anônimo A). A partir do enunciado em questão, é possível destacar a percepção da escrita como uma etapa delimitada em todo o processo em que se compreende a pós-graduação. Por consequência, o enunciador deixa expressa uma 
consciência de que escrever a dissertação/tese não representa a totalidade da experiência com a pós-graduação, justificado pela compreensão desta como "parte". Na sequência, defende-se o status do texto na pós-graduação como elegante e, por tal característica, trabalhoso. Logo abaixo, selecionamos um comentário que interage com a postagem, no qual há a defesa de que a escrita seria o processo que transforma dados em pesquisa.

Em análise à situação comunicativa acima, vemos que a partir dessa experiência a escrita da dissertação/tese pode assumir um caráter dúbio: ao mesmo tempo em que é uma etapa desagradável, traz para os dados do pesquisador o estatuto de pesquisa, validando a existência dos mesmos e se tornando essencial para garantir tal identidade.

Há, ainda, o fator da elegância que, aos olhos do sujeito da postagem, seria algo difícil de ser alcançado. Tomando os pressupostos bakhtinianos da constituição do gênero discursivo, apreende-se que esta elegância diz respeito ao estilo que percorre o conteúdo do texto da dissertação/tese. Acerca do estilo Bakhtin (2011, p. 266) salienta que:

A relação orgânica e indissolúvel do estilo com o gênero se revela nitidamente também na questão dos estilos de linguagem ou funcionais. No fundo, os estilos de linguagem ou funcionais não são outra coisa senão estilos de gênero de determinadas esferas da atividade humana e da comunicação.

Assim, tomando esse panorama de análise, reconhecemos no sujeito da postagem uma relação subalterna em relação ao estilo da linguagem do texto científico. Sendo o estilo o resultado de interações e reconhecimento de práticas de linguagem que se concretizam nas linhas do texto organicamente, infere-se que os sujeitos que o visualizam como algo distante de suas capacidades deixam transparecer, além de uma necessidade técnica de auxílio em redação, uma autoidentificação como indivíduos que estão fora desta comunidade específica, isto é, outsiders, nas palavras de Gee (2001).

Ademais, tais percepções levantadas pelo sujeito da postagem e seu comentador (Comentarista anônimo B) dão indícios de como o sistema da pós-graduação é visualizado a partir das experiências com escrita. Se nessa experiência a escrita é tida como a pior parte, sem, contudo, deixar de ser elemento decisivo na identificação do que é a pesquisa, compreendemos que há aqui a confirmação de que escrever na pós-graduação configura-se como um ritual árduo e complexo, mas que é recompensado com a conferência de autenticidade àqueles que nele se dispõem a participar. 
Quadro 2: Desabafo sobre o processo de orientação²

Postagem: "Estou arrasado...
Meu orientador passou a faca na minha dissertação, cortou
tanta coisa que estou me sentindo dentro do seriado Dexter-
quase esquartejado.
Não tem nada pior do que escrever dias e dias e aí vem o cara
com uma caneta vermelha rabisca tudo, tira capítulos. É a dor
de um parto!
Estou inconsolável... preciso de biscoito galera... Me consolem...
me coloquem nos trilhos novamente!"

Fonte: Comentarista anônimo C (2018).

O excerto 2 traz elementos interessantes que, apesar de não diferirem em alguns aspectos com relação ao excerto 1 , transferem ao processo da escrita uma rede de significações ainda mais intensa. O uso dos vocábulos "dor", "arrasado", "passar a faca", "esquartejado" e "parto", por exemplo, nos permite compreender que as experiências com a escrita, por mais que se assemelhem em processos técnicos, serão experimentadas de maneiras diversas pelos pós-graduandos, devido principalmente aos entornos sociais, históricos e culturais que compõem suas vidas, colaborando na produção de avaliações distintas sobre essa linguagem.

O grande enfoque desta postagem está na forma com que o sujeito pós-graduando (Comentarista anônimo C) encara sua relação com o orientador pós-leitura de seu texto. A partir da descrição das sensações ao receber o texto, nas palavras do autor, rabiscado e "esquartejado" pelo orientador, é possível detectar indícios de que a experiência com a escrita neste caso funde-se com as próprias percepções que o pós-graduando tem de si para além da esfera acadêmica. Tal cenário nos mostra que as conexões estabelecidas entre a escrita na pós-graduação e a vida como um todo produzem, quando essa experiência é frustrada, um mal-estar que ultrapassa a relação de trabalho, atingindo campos emocionais.

A partir da experiência relatada, também compreendemos que o imaginário em torno de a escrita na pós-graduação ser implacavelmente técnica não se sustenta. Tendo em vista o próprio ritmo de trabalho dos pós-graduandos brasileiros de maneira geral e a reação descrita no excerto a uma etapa rotineira do processo de orientação, destacamos que há fatores de ordem emocional, afetiva e criativa que se envolvem com a escrita da dissertação/tese, sendo a técnica da estrutura do gênero e disposição de dados apenas um aspecto de uma dinâmica complexa.

\footnotetext{
${ }^{2}$ A expressão "dar um biscoito" é uma gíria que tem circulado nas redes sociais e cobre o sentido de "dar atenção".
} 
Reiteramos em mencionar como a escrita transforma a relação do orientando com seu orientador. Por mais que circule na pós-graduação o discurso de reconhecimento do papel e responsabilidade do orientador em indicar caminhos de produção científica bem-sucedida, esse papel se inverte, mesmo que temporariamente, na avaliação do pós-graduando ao tipo de intervenção recebida, conforme o excerto 2. Mais uma vez, a linguagem escrita funciona nesta interação como delimitador de relações de poder, sendo também a mesma linguagem a base para o questionamento dessas relações.

Quadro 3: Pergunta sobre o tamanho de uma dissertação Postagem: "Gente, boa tarde, comecei agora a escrever minha dissertação e tenho como prazo até 31/10 (socooorro), quantas páginas tem/teve a dissertação de vocês? Só pra ter uma ideia do que me aguarda e o que eu faço nesse curto espaço de tempo"

Fonte: Comentarista anônimo D (2018).

No excerto 3 somos confrontados com outra indagação a respeito da escrita na pósgraduação: o tamanho do texto de dissertações e teses. O sujeito em questão (Comentarista anônimo D) lança ao grupo sua dúvida, que contém traços de preocupação (ilustrado pela presença de "socoorro", por exemplo), a respeito do tamanho em páginas de uma dissertação.

Tal indagação nos permite compreender outras perspectivas acerca do estatuto do texto acadêmico na pós-graduação brasileira. Nesta situação, a dissertação tem sua composição dialógica como gênero discursivo desconstruída, de modo que se possa alcançar um quantitativo de páginas dentro de um prazo específico. Em adição às reflexões realizadas acerca do excerto 1 , é possível verificar certos contornos não só definidos, mas rígidos em torno do texto e do gênero acadêmico, que, quando alcançados, conferem ao sujeito pesquisador um imaginário de qualidade, partindo do formato e do estilo.

Assim, os enunciados trazidos até aqui deixam entrever que o texto acadêmico é refinado, trabalhoso e longo (aspectos típicos do plano estrutural e estético do texto), porém nesses mesmos enunciados não se é possível extrair posicionamentos pertinentes ao conteúdo ou impacto social dessas produções.

Este cenário nos permite não só compreender melhor percepções dos sujeitos da pósgraduação, mas também assimilar com mais clareza como se sistematiza essa esfera. Seja pelo produtivismo ou por expectativas em torno da intelectualidade e habilidade com a redação acadêmica, a escrita na pós-graduação carrega em si elementos e processos que permitem ou inibem os sujeitos a desenvolverem uma relação de pertença. 


\section{Considerações finais}

A partir dos debates propostos e do exercício de análise anteriores é possível traçar algumas considerações sobre as formas com que a pós-graduação brasileira interage com a escrita, bem como de que formas os estudos em letramentos acadêmicos se estabelecem como uma seara potente para a discussão dessa problemática.

Apesar de os enunciados que compuseram o corpus não poderem ser compreendidos como uma voz uníssona na pós-graduação brasileira, é possível apreender de seu discurso que há um relacionamento complexo com a escrita nessa esfera acadêmica. Qualificamos como complexo por unir tanto uma perspectiva que superestima esta prática, trazendo-a para o patamar de processo dificilmente apreensível pelos sujeitos em formação, quanto uma visão que a recusa, através do reconhecimento de etapa desagradável no percurso de um mestrado ou doutorado.

Tal indício mostra-se como um forte mobilizador de atitudes dentro dos letramentos acadêmicos, pois nos proporciona o debate acerca de como se tornam cada vez mais complexas as relações do sujeito com a escrita, desmistificando, por consequência, a ideia de que a pós-graduação não necessitaria de um olhar igualmente atento, concretizado em práticas de formação que desconstruam a escrita como sinônimo de sofrimento.

Certamente, este trabalho não contempla de maneira integral todas as problemáticas nas quais os sujeitos da esfera acadêmica entram em tensão, porém configura-se como uma prática problematizadora que busca levantar questões próprias dos estudos da linguagem, na perspectiva de fomentar suportes que dialoguem com as identidades diversas desta esfera.

\section{Referências}

ALVES, M. F.; MOURA, L. A escrita de artigo acadêmico na universidade: autoria x plágio. Ilha do Desterro: A Journal of English Language, Literatures in English and Cultural Studies, v. 69, n. 3, p. 77-94, 2016. https://doi.org/10.5007/2175-8026.2016v69n3p77

ASSOCIAÇÃO DE PÓS-GRADUANDOS/AS IEDA DELGADO - UNIVERSIDADE DE BRASÍLIA. Sofrimento mental na pós-graduação da Universidade de Brasília: situação e propostas de soluções. Resumo de questionário. Disponível em: http://www.anpg.org.br/wpcontent/uploads/2018/04/Resumo-question\%C3\%A1rio-2.0.pdf. Último acesso em 23/02/2019.

BAKHTIN, M. Estética da Criação Verbal. São Paulo: Martins Fontes, 2011.

BARTON, D.; HAMILTON, M. Literacy practices. In: BARTON, D.; HAMILTON, M.; IVANIC, R. Situated literacies: reading and writing in context. London/New York: Routledge, 2000. p. 715. 
BESSA, J. C. R. O discurso citado na macroestrutura textual de artigos científicos de jovens pesquisadores. Ilha do Desterro: A Journal of English Language, Literatures in English and Cultural Studies, v. 69, n. 3, p. 45-62, 2016 . https://doi.org/10.5007/21758026.2016v69n3p45

BRAMBILA, G. A produção de texto na "Era Enem": subjetividade e autoria no contexto político-pedagógico brasileiro contemporâneo. 139 p. 2017. Dissertação de mestrado Programa de Pós-graduação em Estudos Linguísticos da Universidade Federal do Espírito Santo, Vitória, 2017.

CERUTTI-RIZZATTI, M. E.; DELLAGNELO, A. Desafios à educação para a autoria na esfera acadêmica. Ilha do Desterro: A Journal of English Language, Literatures in English \& Cultural Studies, v. 69, n. 3, p. 63-73, 2016. https://doi.org/10.5007/2175-8026.2016v69n3p63

CRUZ, R. N. Becker e o silêncio sobre a escrita na pós-graduação: soluções antigas para o cenário brasileiro atual? Psicologia \& Sociedade, v. 30, p. 1-7, 2018. https://doi.org/10.1590/1807-0310/2018v30167038

FACEBOOK. Bolsistas Capes. $2019 . \quad$ Disponível em: https://www.facebook.com/groups/308640309159780/. Último acesso em 03/07/2019.

FIAD, R. S. A escrita na universidade. Revista da ABRALIN, v. Eletrônico, n. Especial, p. 357-369, 2a parte, 2011. https://doi.org/10.5380/rabl.v10i4.32436

FIAD, R. S. Algumas considerações sobre os letramentos acadêmicos no contexto brasileiro. Pensares em Revista, n. 6, p. 23-34, 2015. https://doi.org/10.12957/pr.2015.18424

FILHO, U. C.; TORGA, V. L. M. Língua, Discurso, Texto, Dialogismo e Sujeito: compreendendo os gêneros discursivos na concepção dialógica, sócio-histórica e ideológica da língua(gem). In: ANAIS DO I CONGRESSO NACIONAL DE ESTUDOS LINGUÍSTICOS (UFES), 2011. p. 1-4.

FISCHER, A. Os usos da língua na construção de sujeitos letrados: relações entre a esfera escolar e a acadêmica. Acta Scientiarum. Language and Culture, Maringá, v. 32, n. 2, p. 215224, 2010. https://doi.org/10.4025/actascilangcult.v32i2.9257

FISCHER, A.; HOCHSPRUNG, V. Prática de escrita na universidade: a perspectiva dos letramentos acadêmicos sobre produções de estudantes de Letras. Miguilim - Revista Eletrônica do Netlli, Crato, v. 6, n. 3, p. 44-66, 2017.

FRANÇA, K. C. F. A filiação teórica na escrita do pesquisador em formação: uma análise sobre a genealogia do dizer acadêmico pelas formas de língua. 176 p. 2018. Tese de Doutorado. Programa de pós-graduação em Estudos da Linguagem da Universidade Federal do Rio Grande do Norte, 2018.

GEE, J. P. Social linguistics and literacies. Ideology in Discourses. 2. ed. London/Philadelphia: The Farmer Press, 1999.

GEE, J. P. "Literacy, Discourse, and Linguistics: Introduction and What Is Literacy?". In: CUSHMAN, E. et al (Eds.). Literacy: A Critical Sourcebook. New York: Bedford/St. Martin's, 525544, 2001.

GINZBURG, C. Mitos, Emblemas, Sinais: morfologia e história. São Paulo: Companhia das Letras, 1986. 
MARINHO, M. A escrita nas práticas de letramento acadêmico. Revista Brasileira de Linguística Aplicada, Belo Horizonte, v. 10, n. 2, p. 363-386, 2010. https://doi.org/10.1590/S1984$\underline{63982010000200005}$

MOITA LOPES, L. P. Da aplicação da Linguística à Linguística Aplicada Indisciplinar. In: PEREIRA, R. C.; ROCA, P. Linguística Aplicada: um caminho com diferentes acessos. Editora Contexto, SP, p. 11-24, 2009.

SANTOS, F. T. C. R; GARCIA, S. S.; AQUINO, J. G. Um olhar estrangeiro à literatura: Foucault, escrita, experiência. Ecos, v. 1, n. 8, p. 14-28, 2017.

STREET, B. Introduction: the new literacy studies. In: STREET, B. Cross-cultural approaches to literacy. Great Britain: Cambridge University Press, p. 1-21, 1995.

VOLÓCHINOV. V. (Círculo de Bakhtin). Marxismo e Filosofia da Linguagem. Problemas fundamentais do método sociológico na ciência da linguagem. Tradução: Sheila Grillo e Ekaterina Américo. Editora 34, 2017.

VIDON, L. N. Dialogia, estilo e argumentação no trabalho de um sujeito com a linguagem. 168 p. 2003. Tese de Doutorado. Instituto de Estudos da Linguagem, Unicamp, São Paulo, 2003.

Recebido em: 24/02/2019

Aceito em: $14 / 05 / 2019$ 